\title{
Time of Birth, Residential Solar Radiation and Age at Onset of Multiple Sclerosis
}

\author{
Tzu-Yun McDowella, ${ }^{\mathrm{b}}$ Sania Amr ${ }^{\mathrm{b}}$ Patricia Langenberg ${ }^{\mathrm{b}}$ Walter Royal $^{\mathrm{a}, \mathrm{c}}$ \\ Christopher Bever $^{a, c}$ William J. Culpepper ${ }^{a, b}$ Douglas D. Bradham ${ }^{a, d}$ \\ ${ }^{a}$ MS Center of Excellence-East, Baltimore VAMC, Departments of ${ }^{b}$ Epidemiology and Preventive Medicine, and \\ 'Neurology, University of Maryland School of Medicine, Baltimore, Md., and ${ }^{\mathrm{d} D e p a r t m e n t}$ of Preventive Medicine \\ and Public Health, University of Kansas School of Medicine-Wichita, Wichita, Kans., USA
}

\section{Key Words}

Multiple sclerosis · Age at onset, MS · Solar radiation • Latitude

\begin{abstract}
Backgrounds/Aim: Gestational and early life events have been suggested to contribute to multiple sclerosis (MS) susceptibility. We assessed the effects of time and place of birth on the age at onset of MS symptoms. Methods: We selected a national cohort of 967 veterans from the Multiple Sclerosis Surveillance Registry for whom month and season (time) of birth, and birthplace (city and state) were available. Multiple linear regression analyses were used to examine the association between time of birth, birthplace latitude and solar radiation, and the age at onset of MS symptoms among the study sample. Results: Patients with a relapsing form of the disease (R-MS), who were born in winter and whose birthplace was in low solar radiation areas, had disease symptom onset on average 2.8 years earlier than those born in seasons other than winter and in medium- and high-solar radiation areas ( $p=0.02)$. Conclusions: These results suggest that exposure early in life to geographical and seasonal factors, possibly related to the protective effect of sunlight, and thus
\end{abstract}

vitamin D, is associated with a delay in MS symptom onset. Other larger studies are required to examine the period-specific (from conception to adulthood) environmental factors that are associated with MS susceptibility.

Copyright $\odot 2010$ S. Karger AG, Basel

\section{Introduction}

A growing body of evidence supports the concept that life events during gestational and postnatal periods have long-lasting effects on the risk and progression of a variety of chronic diseases, including multiple sclerosis (MS), which is an immune-mediated inflammatory and neurodegenerative disease $[1,2]$. The etiology of MS is thought to be a complex interplay between genetic and environmental risk factors [3-5] with a well-documented geographical distribution across populations and low prevalence in areas at low latitude $[6,7]$.

Geographical location at birth has been found to be associated with age at MS onset. In one study, both monozygotic and dizygotic twins born in the northern areas (at or above $41^{\circ} \mathrm{N}$ ) were diagnosed on an average 2-3 years earlier than twin pairs born elsewhere [8]. Timing of en-

\section{KARGER}

(C) 2010 S. Karger AG, Basel

Fax +41613061234 E-Mail karger@karger.ch www.karger.com www.karger.com/ned
Tzu-Yun McDowell

MS Center of Excellence-East, Baltimore VAMC

10 N. Green Street

Baltimore, MD 21201 (USA)

Tel. +1 410605 7414, Fax +1 410605 7705, E-Mail Tzu-Yun.Chang-McDowell@va.gov 
vironmental exposures has also been found to relate to MS risk. A number of studies have suggested that the risk of developing MS was associated with the affected individual's place of residence at birth [8] and early in life [9]. The month of birth was suggested to play a role in the development and clinical course of MS [10-13]. A large population-based study found that fewer MS patients were born in November compared to population- and family-based controls [13]. This finding, consistent with other studies of different populations in northern countries [14-16], supports the concept of seasonally varied and maternally mediated environmental exposures as contributing risk factors for MS.

Accordingly, sunlight and vitamin D have gained considerable support for their potential role in determining MS susceptibility [3, 4, 17-20]; seasonal variation in maternal concentrations of vitamin $\mathrm{D}$, which is mainly produced in the skin after exposure to sunlight and ultraviolet radiation which are known to be related to latitude, might have a bearing on the development of the fetal immune system, central nervous system, or both, and hence on MS susceptibility.

Although plausible, the associations between month and place of birth, age at MS onset, and related outcomes (phenotype, and clinical course) remain unconfirmed. We used a national cohort of veterans with MS to examine the associations between age at disease symptom onset and (1) time of birth and (2) the solar radiation level of the birthplace.

\section{Methods}

\section{Study Population}

The Veterans Health Administration (VHA)-Multiple Sclerosis Surveillance Registry (MSSR) is a population-based, self-report registry of veterans with MS that has been described in detail elsewhere [21]. Briefly, the MSSR cohort was established in 2007 through a mail-based survey under the supervision of the VHA's Multiple Sclerosis Center of Excellence-East (MSCoE-East) in Baltimore, Md. From all veterans identifiable in the VHA system with possible MS, confirmed MS cases were selected using the statistical algorithm of Culpepper et al. [22]. From this effective sampling pool, a regionally stratified, random sample of MS cases $(n=3,905)$ was then targeted for the MSSR. Female veterans were oversampled to make it more representative of the general (non-veteran) population. The goal of the survey was to obtain directly from the participants detailed MS-specific information that is not included in the routine VHA databases, such as year at onset of MS symptom and MS subtype.

The survey was mailed in three phases using the method of Edwards et al. [23] to maximize the overall response rate. Survey packets consisted of: a cover letter describing the project; a consent form acknowledging their willingness to participate in the
VHA MSSR; a HIPAA form, and the survey. The University of Maryland Institutional Review Board and the VHA Research and Development Committee at Baltimore VAMC approved the present study.

As of March 2009, a total of 1,381 MS veterans had responded to the survey ( $35 \%$ response rate), from which we obtained information on demographics, and MS-related clinical data and outcomes. Our preliminary analysis showed that demographic and clinical characteristics of the MSSR are comparable to those of various published MS cohorts [24-26]. Thus, the MSSR can serve as a useful cohort to study MS-related risk factors and outcomes [21].

We included only participants who were born in the United States and for whom we had complete data regarding date and place of birth, age at symptom onset, and age at diagnosis ( $\mathrm{n}=$ 1,257). To limit heterogeneity due to childhood or very late onset of MS, or diagnostic delay, we restricted the study sample ( $\mathrm{n}=$ 967 ) to those whose onset of symptoms occurred between 18 and 64 years of age and for whom the MS diagnosis was made no later than 10 years after the onset of symptoms.

\section{Age at Onset}

Participants reported the year when they first experienced symptoms that could be related to MS and the year when they were diagnosed, and we calculated the respective ages using their date of birth.

\section{Time of Birth}

Month and season of birth were used as indicators of time of birth. The season of birth variable was generated as follows: spring (March-May), summer (June-August), fall (September-November) and winter (December-February). We examined the association between each indicator and age at MS symptom onset separately.

\section{Place of Birth}

Using the city and state in which participants were born, we derived the latitude [27] and the solar radiation level of the birthplace. Latitude was used as a continuous, as well as a categorical variable. Latitude was either dichotomized into 'northern' $\left(\geq 41^{\circ} \mathrm{N}\right)$ and 'not northern' $\left(<41^{\circ} \mathrm{N}\right)$, or categorized as southern $\left(\leq 37^{\circ} \mathrm{N}\right)$, middle $\left(>37\right.$ to $\left.<41^{\circ} \mathrm{N}\right)$, and northern $\left(\geq 41^{\circ} \mathrm{N}\right)$. For each participant's state of birth, the solar radiation level was obtained from a previously published map of the annual mean daily solar radiation by the United States Weather Bureau $[28,29]$ and expressed in Langley as thermochemical calories per square centimeter; a measure that factors in latitude and climate conditions. Such a method to estimate solar radiation reaching the ground has been used previously $[30,31]$. We assigned one of three solar radiation levels: low, medium or high to each participant's birth place (fig. 1) [29].

\section{Other Covariates}

Participants reported their general smoking history as one of several choices, which were further grouped into three categories of smokers: never/social (infrequently smoke, at parties/bar), light/regular ( $\leq 1 \mathrm{pack} /$ day), and moderate/heavy ( $>1 \mathrm{pack} /$ day). Other important variables such as sex, race, MS subtype, and years of education were obtained from the survey. 
Fig. 1. Mean daily solar radiation (source: US Department of Commerce, 1968) superimposed on the longitude and latitude map of the United States [29]. Low-level solar radiation (<350 Langley) states include: AK, CT, ME, MA, MI, MN, NH, NY, $\mathrm{OH}, \mathrm{OR}, \mathrm{PA}, \mathrm{RI}, \mathrm{VT}, \mathrm{WA}$ and WI. Medium-level solar radiation ( $\geq 350-400$ Langley) states include: AR, DE, DC, ID, IL, IN, IA, KS, KY, MD, MO, MT, NE, NJ, NC, ND, SD, TN, VA, and WV. High-level solar radiation ( $>400$ Langley) states include: AL, AZ, CA, CO, FL, GA, HI, LA, MS, NV, NM, OK, SC, TX, UT, WY, and PR.

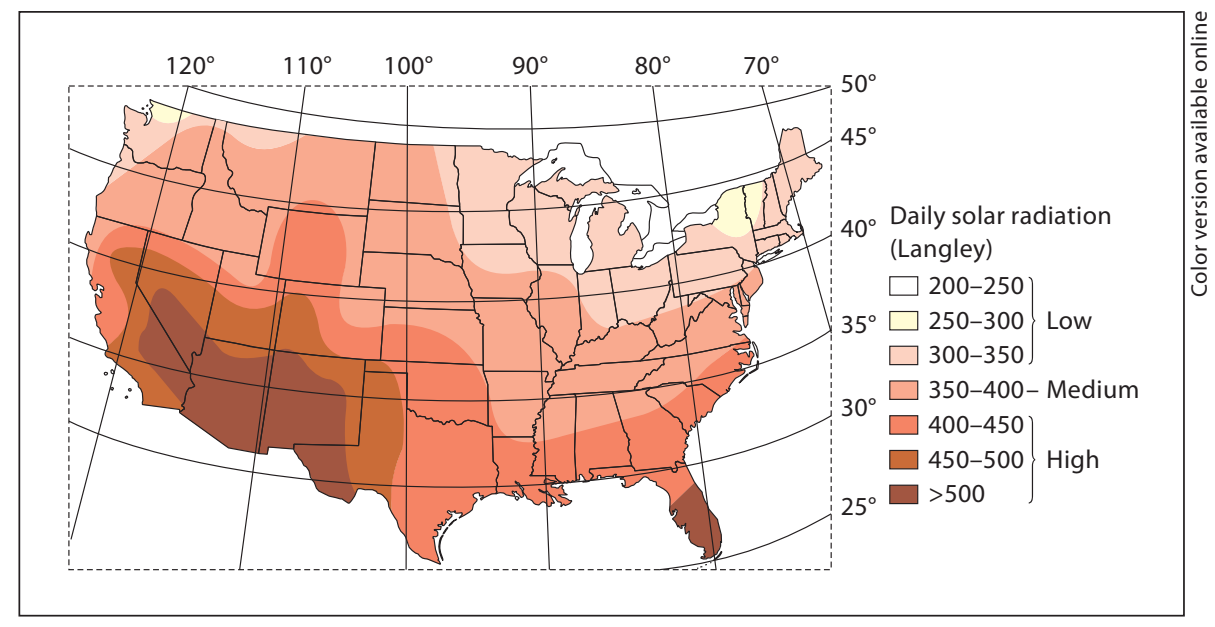

Statistical Analyses

The main outcomes were age at onset of MS symptoms and age at diagnosis. The main study variables were time of birth (month and season), and birthplace latitude and solar radiation level. Univariate and bivariate analyses were performed to examine the variables' distributions and the unadjusted associations between the main study variables and outcomes. $t$ test and one-way ANOVA were used to determine the statistical significance of such associations. We used multivariable linear regression models to examine the relationship between time and place of birth, and age at MS symptoms onset, while controlling for covariates such as sex, race, and history of smoking. The potential effect modifier of the covariates was assessed in these models. We performed stratified analysis and fit separate regression models for each MS subtype. All analyses were performed using SAS version 9.1.

\section{Results}

Table 1 summarizes the demographic and clinical characteristics of the study sample. The average age at onset of MS symptoms was $34.6 \pm 9.9$ (range 18-62) years, with $>70 \%$ of patients reporting symptoms onset before age 40 years, and the mean age at diagnosis was $36.9 \pm 9.7$ years. We divided the patients into 2 groups based on disease characteristics at onset: (1) relapsing MS (R-MS) for those who experienced relapses/exacerbations at onset and during the early course of the disease including patients with relapse-remitting and secondary progressive MS, and (2) progressive MS (P-MS) for those with progressively worsening disease with or without experiencing relapses later in the disease course. The 731 (76\%) patients with R-MS, had significantly earlier onset of disease symptoms (33.8 \pm 9.5 years) than those with the P-MS $(36.9 \pm 10.6$ years; $p<0.001)$. Fifty-three per- cent of the patients with R-MS were female, whereas males represented $70 \%$ of those with P-MS. Forty-one to $44 \%$ of MS patients were born in low solar radiation ( $<350$ Langley) and northern (latitude $\geq 41^{\circ}$ ) areas. The season of birth was evenly distributed across the study sample.

Given that fewer patients were born in areas with high solar radiation ( $>400$ Langley), we combined medium and high versus low levels. Because similar results were observed using age at diagnosis or age at onset of MS symptoms as the main outcome, we only reported results for the latter. R-MS patients born in medium/high solar radiation areas were on average 2 years older at the onset of their MS symptoms, compared to those born in low solar radiation areas $(\mathrm{p}=0.009)$. Those born in the northern part of the US (latitude $\geq 41^{\circ}$ ) were slightly younger $(33.3 \pm 8.9$ years) when they started experiencing MSrelated symptoms than those born elsewhere in the country (34.3 \pm 9.9 years); although the difference was not statistically significant ( $p=0.17$; table 2$)$. Evaluation of latitude as three levels or as quartiles showed similar results: the higher the latitude, the younger the age at symptom onset. Among patients with P-MS, the mean age at onset of MS symptoms did not differ, either by the latitude or the solar radiation level of the birthplace. Neither month nor season of birth was significantly associated with age at onset for either R-MS or P-MS patients.

We then stratified data by solar radiation levels to examine the effects of month and season of birth, respectively, on the age at MS symptom onset among R-MS patients. A significant trend for the month of birth was found ( $p=0.047$ ) among those whose birthplace suggested exposure to medium/high solar radiation; the R-MS 
Table 1. Demographics and clinical characteristics of the study population

\begin{tabular}{|c|c|c|c|}
\hline & $\begin{array}{l}\text { Study population }{ }^{\mathrm{a}} \\
(\mathrm{n}=967)\end{array}$ & $\begin{array}{l}\text { Relapse-remitting MS } \\
(\mathrm{n}=731)\end{array}$ & $\begin{array}{l}\text { Progressive MS } \\
(\mathrm{n}=236)\end{array}$ \\
\hline \multicolumn{4}{|l|}{ Demographic characteristics } \\
\hline Age, years (mean $\pm S D)$ & $53.2 \pm 9.7$ & $52.0 \pm 9.8$ & $57.0 \pm 10.6$ \\
\hline \multicolumn{4}{|l|}{ Race, n (\%) } \\
\hline White & $831(85.9)$ & $627(85.7)$ & $204(86.4)$ \\
\hline Black & $136(14.1)$ & $104(14.2)$ & $32(13.6)$ \\
\hline \multicolumn{4}{|l|}{ Sex, n (\%) } \\
\hline Female & $459(47.8)$ & $389(53.5)$ & $70(29.9)$ \\
\hline Male & $502(52.2)$ & $338(46.5)$ & $164(70.1)$ \\
\hline \multicolumn{4}{|l|}{ Education } \\
\hline Average years (range) & $14.7 \pm 2.7(0-21)$ & $14.8 \pm 2.6(0-21)$ & $14.4 \pm 2.8(7-21)$ \\
\hline \multicolumn{4}{|l|}{ Smoking history, $\mathrm{n}(\%)$} \\
\hline Never/social smoker & $417(44.6)$ & $328(46.0)$ & $424(44.4)$ \\
\hline Light/regular smoker & $210(22.4)$ & $166(23.3)$ & $213(22.3)$ \\
\hline Moderate/heavy smoker & $309(33.0)$ & $219(30.7)$ & $317(33.2)$ \\
\hline \multicolumn{4}{|l|}{ Birthplace } \\
\hline \multicolumn{4}{|l|}{ Solar radiation, $\mathrm{n}(\%)$} \\
\hline Low: <350 Langley & $417(43.1)$ & $313(42.8)$ & $104(44.1)$ \\
\hline Medium: 350-400 Langley & $329(34.0)$ & $255(34.9)$ & $74(31.4)$ \\
\hline High: >400 Langley & $221(22.9)$ & $163(22.3)$ & $58(24.6)$ \\
\hline \multicolumn{4}{|l|}{ Latitude, n (\%) } \\
\hline Northern: $\geq 41^{\circ}$ & $407(42.1)$ & $309(42.3)$ & $98(41.5)$ \\
\hline Middle: $37-<41^{\circ}$ & $345(35.7)$ & $261(35.7)$ & $84(35.6)$ \\
\hline Southern: $<37^{\circ}$ & $215(22.2)$ & $161(22.0)$ & $54(22.9)$ \\
\hline Average latitude, degrees (range) & $39.7 \pm 4.5(21.2-64.8)$ & $39.8 \pm 4.5(21.2-64.8)$ & $39.4 \pm 4.4(25.8-48.2)$ \\
\hline \multicolumn{4}{|l|}{ Season of birth } \\
\hline Spring & $241(24.9)$ & $182(24.9)$ & $59(25.0)$ \\
\hline Summer & $247(25.5)$ & $188(25.7)$ & $59(25.0)$ \\
\hline Fall & $246(25.5)$ & $185(25.3)$ & $61(25.9)$ \\
\hline Winter & $233(24.1)$ & $176(24.1)$ & $57(24.2)$ \\
\hline \multicolumn{4}{|l|}{$\begin{array}{l}\text { Clinical characteristics } \\
\text { Age at MS (mean } \pm \mathrm{SD})\end{array}$} \\
\hline Symptoms onset & $34.6 \pm 9.9$ & $33.9 \pm 9.5$ & $37.0 \pm 10.6$ \\
\hline Diagnosis & $36.9 \pm 9.7$ & $36.1 \pm 9.4$ & $39.3 \pm 10.3$ \\
\hline
\end{tabular}

patients born in winter were on an average younger at MS symptom onset $(32.7 \pm 1.0$ years) than those born in other seasons ( $35.3 \pm 0.6$ years), only when their birthplaces were in median/high solar radiation areas ( $\geq 350$ Langley; $\mathrm{p}=0.02$ ).

\section{Multiple Regression Models}

A regression model was fitted for R-MS patients to further examine the significant association between season of birth, birthplace solar radiation and age at onset, while adjusting for other known MS risk factors and covariates. Time of birth and solar radiation data were combined

Time of Birth, Residential Solar Radiation and Age at Onset of Multiple Sclerosis and re-categorized into four levels: winter born/low solar radiation (reference group), winter born/medium-high solar radiation, other seasons/low solar radiation and other seasons/medium-high solar radiation. Among R-MS patients, those born between March and November (not in winter) and whose birthplace was in a mediumhigh solar radiation area had symptom onset on average 2.8 years later than those born in winter in a low solar radiation area ( $\mathrm{p}=0.02,95 \% \mathrm{CI} 0.36-5.22$; table 3 ). Females and patients with higher education levels had earlier onset of symptoms. Patients who reported being moderate/heavy smokers had symptom onset on average

Neuroepidemiology 2010;34:238-244 
2.5 years later than those who never smoked or smoked only socially ( $\mathrm{p}=0.002,95 \%$ CI $0.91-4.14$ ).

Different models were fitted to examine associations between latitude (continuous and categorical variables) and age at onset. Latitude (continuous variable) was

Table 2. Mean age at onset of MS symptoms by seasonal and birthplace characteristics among veterans with MS

\begin{tabular}{|c|c|c|c|c|}
\hline & \multicolumn{2}{|c|}{$\begin{array}{l}\text { Relapsing MS } \\
(\mathrm{n}=731)\end{array}$} & \multicolumn{2}{|c|}{$\begin{array}{l}\text { Progressive MS } \\
(\mathrm{n}=236)\end{array}$} \\
\hline & $\begin{array}{l}\text { symptom } \\
\text { onset }\end{array}$ & $\begin{array}{l}\mathrm{p} \\
\text { value }^{\mathrm{a}}\end{array}$ & $\begin{array}{l}\text { symptom } \\
\text { onset }\end{array}$ & $\begin{array}{l}\mathrm{p} \\
\text { value }^{\mathrm{a}}\end{array}$ \\
\hline \multicolumn{5}{|l|}{ Solar radiation } \\
\hline Low & $32.8 \pm 8.8$ & \multirow{2}{*}{0.009} & $37.2 \pm 11.1$ & \multirow{2}{*}{0.87} \\
\hline Medium-high & $34.7 \pm 9.9$ & & $36.8 \pm 10.3$ & \\
\hline \multicolumn{5}{|l|}{ Latitude } \\
\hline Northern $\left(\geq 41^{\circ} \mathrm{N}\right)$ & $33.3 \pm 8.9$ & \multirow[b]{2}{*}{0.17} & $37.2 \pm 11.9$ & \multirow[b]{2}{*}{0.80} \\
\hline Other & $34.3 \pm 9.9$ & & $36.8 \pm 9.7$ & \\
\hline \multicolumn{5}{|l|}{ Season } \\
\hline Spring & $34.1 \pm 10.3$ & \multirow{4}{*}{0.31} & $36.5 \pm 11.9$ & \multirow{4}{*}{0.99} \\
\hline Summer & $34.4 \pm 9.2$ & & $37.4 \pm 10.1$ & \\
\hline Fall & $34.3 \pm 9.4$ & & $37.2 \pm 11.2$ & \\
\hline Winter & $32.7 \pm 9.2$ & & $36.9 \pm 9.4$ & \\
\hline
\end{tabular}

${ }^{a} t$ test and one-way ANOVA were used to compare dichotomized and multilevel variables, respectively. found to be negatively associated with age at onset of MS, although not significant $(\mathrm{p}=0.10)$, in patients with R-MS; each $10^{\circ}$ increase in latitude was associated with an earlier onset of MS symptoms by an average of 1.3 years $(95 \%$ CI -2.8 to -0.3 ).

We found no associations between either birthplace solar radiation level or latitude and age at MS symptoms onset among patients with P-MS.

\section{Discussion}

We found that R-MS patients, who were born in winter and whose birthplace was in low solar radiation areas, had disease symptom onset on an average 2.8 year earlier than those born in seasons other than winter and in medium-high solar radiation areas. Similar associations, although not statistically significant, were observed between high latitude birthplace (reflecting low solar radiation) and early onset of MS symptom. No association was found between age at onset and time of birth or birthplace among patients with progressive disease.

This is the first study to address the age at MS symptom onset and both the latitude and solar radiation level of birthplace, as well as the time of birth. Previous studies have investigated the associations either between age at MS onset and latitude $[8,32]$ or between month of birth

Table 3. Multivariable linear regression of age at MS symptom onset on birthplace solar radiation levels and season of birth adjusted for important covariates in patients with R-MS

\begin{tabular}{|c|c|c|c|}
\hline \multirow[t]{2}{*}{ Variables $^{\mathrm{a}}$} & \multicolumn{3}{|c|}{ Relapsing MS $(\mathrm{n}=731), \mathrm{R}^{2}=8.9$} \\
\hline & estimate (SE) & $95 \% \mathrm{CI}$ & $\mathrm{p}$ value \\
\hline Intercept & $42.16(2.42)$ & $37.41,46.91$ & $<0.0001$ \\
\hline \multicolumn{4}{|l|}{ Birth season and solar radiation } \\
\hline Winter/low solar radiation & 0 & - & - \\
\hline Winter/medium-high solar radiation & $0.91(1.54)$ & $-2.12,3.9$ & 0.56 \\
\hline Other seasons/low solar radiation & $0.07(1.26)$ & $-2.41,2.55$ & 0.95 \\
\hline Other seasons/medium-high solar radiation & $2.79(1.24)$ & $0.36,5.22$ & 0.02 \\
\hline \multicolumn{4}{|l|}{ Race } \\
\hline Black & $-0.80(1.01)$ & $-2.80,1.19$ & 0.43 \\
\hline \multicolumn{4}{|l|}{ Sex } \\
\hline Male & $2.68(0.71)$ & $1.29,4.07$ & 0.0002 \\
\hline Education, years & $-0.48(0.14)$ & $-0.75,-0.21$ & 0.0005 \\
\hline \multicolumn{4}{|l|}{ Smoking history } \\
\hline Never/social smoker & 0 & - & - \\
\hline Light/regular smoker & $0.92(0.88)$ & $-0.81,2.65$ & 0.30 \\
\hline Moderate/heavy smoker & $2.52(0.82)$ & $0.91,4.14$ & 0.002 \\
\hline
\end{tabular}

a All the variables listed were included in the final model. 
and MS-related outcomes [11-13]. Our data showed an average age at MS symptom onset that decreases with increasing latitude that is consistent with prior reports $[8$, 32]. Associations between the month of birth and either the risk of developing MS $[13,14,16]$ or the clinical course of the disease [11, 12] have been previously reported. These studies suggest that some environmental factor(s) during gestational periods might play a role in determining MS susceptibility and potentially the course of the disease $[2,11-13]$. Levels of vitamin D in humans, mainly produced through skin synthesis following exposure to solar radiation and thus subject to geographical and seasonal variations, were proposed as one of the possible explanations for the association between time of birth and MS risk [10] as well as for the geographical distribution of MS prevalence $[6,33]$. Cumulative evidence has supported vitamin $\mathrm{D}$ as a strong immune modulator and protective against development of MS [3, 18, 34, 35]. In our study, the association of early MS onset with a low solar radiation birthplace and winter season supports the concept that sun exposure before or at birth, thus the maternal vitamin D level, influences the disease course; possibly by modulating the development of the central nervous system and/or immune system in the fetus. Whether or not our findings relate to maternal or perinatal vitamin $\mathrm{D}$ levels or some other seasonally varied environmental factors in early life remains to be established.

We did not observe any associations between time of birth, birthplace solar radiation and age at MS onset among patients with P-MS. These patients are known to have later onset of the disease, and possibly exposure to other environmental factors later in life. Indeed, Pugliatti et al. [36] suggested that MS clinical heterogeneity might depend on different causative mechanisms. Consistent with our results, Sadovnick et al. [12] found that a month of birth effect was observed in relapsing-remitting MS but not primary progressive MS patients. Furthermore, the sample size of P-MS patients in our study was relatively small to allow examination of complex interactions among variables.

We found that patients who classified themselves as a moderate or heavy smoker had later onset of the disease compared to those who were never or social smokers. This result should be interpreted with caution. This is a cross-sectional study the scope of which was not to address smoking as risk factor for MS, and participants were only asked to describe their smoking status in general, but not their smoking history before their disease onset. We did not have sufficient information to investigate whether or not smoking affects the age at MS symp- tom onset. An alternative explanation of the observed findings is smokers' health behavior that is different from non-smokers; e.g., patients who smoked heavily might be less health conscious and not aware of clinical symptoms at an earlier stage than those who never smoked. Indeed, in a large cohort of MS patients, Marrie et al. [37] reported increased delay in MS diagnosis among smokers, compared to non-smokers.

This study has several limitations, some of which are inherent to its cross-sectional design. Despite oversampling female veterans with MS, our female to male ratio was lower than that of the MS population in the US; hence our study might not be generalizable. Furthermore, we did not examine actual levels of solar radiation at the birthplace or the maternal level of vitamin D; instead, we used proxies for these variables. Future studies are needed to examine more comprehensively the effects of multiple environmental and behavioral risk factors on MSrelated outcomes.

In summary, our study suggests that exposure early in life to geographical and seasonal factors, possibly related to the protective effect of sunlight and thus vitamin $\mathrm{D}$, is associated with a delay in the age at MS symptom onset. Other larger studies are required to examine the periodspecific (from conception to adulthood) environmental factors that are potentially associated with MS susceptibility.

\section{Acknowledgements}

This study was supported by a research grant from Bayer Pharmaceuticals, Inc. (formerly Berlex). Study personnel were supported in part by a merit grant (Examining Health Care Patterns and MS Outcomes with VHA and Medicare Data-IIR 05-205) funded by the Department of Veteran Affairs, Veterans Heath Administration, Office of Research and Development, HSR\&D Service and the VHA MS Center of Excellence-East.

\section{Disclaimer}

The views expressed in this article are those of the authors and do not necessarily reflect the position or policy of the Department of Veterans Affairs or the United States Government. 


\section{References}

1 Gluckman PD, Hanson MA: Living with the past: evolution, development, and patterns of disease. Science 2004;305:1733-1736.

$\checkmark 2$ Goodin DS: The causal cascade to multiple sclerosis: a model for MS pathogenesis. PLoS One 2009; 4:e4565.

$\checkmark 3$ Ascherio A, Munger KL: Environmental risk factors for multiple sclerosis. Part II: noninfectious factors. Ann Neurol 2007;61:504513.

$\checkmark 4$ Ascherio A, Munger KL: Environmental risk factors for multiple sclerosis. Part I: the role of infection. Ann Neurol 2007;61:288-299.

$\checkmark 5$ Kantarci O, Wingerchuk D: Epidemiology and natural history of multiple sclerosis: new insights. Curr Opin Neurol 2006;19:248254.

-6 Kurtzke JF, Beebe GW, Norman JE Jr: Epidemiology of multiple sclerosis in US veterans: 1. Race, sex, and geographic distribution. Neurology 1979;29:1228-1235.

$\checkmark 7$ McLeod JG, Hammond SR, Hallpike JF: Epidemiology of multiple sclerosis in Australia. With NSW and SA survey results. Med J Aust 1994;160:117-122.

8 Islam T, Gauderman WJ, Cozen W, Hamilton AS, Burnett ME, Mack TM: Differential twin concordance for multiple sclerosis by latitude of birthplace. Ann Neurol 2006;60: 56-64.

9 Hammond SR, English DR, McLeod JG: The age-range of risk of developing multiple sclerosis: evidence from a migrant population in Australia. Brain 2000;123:968-974.

10 Wiberg M, Templer DI: Season of birth in multiple sclerosis in Sweden: replication of Denmark findings. J Orthomol Med 1994;9: 71-74.

11 Tremlett HL, Devonshire VA: Does the season or month of birth influence disease progression in multiple sclerosis? Neuroepidemiology 2006;26:195-198.

$\checkmark 12$ Sadovnick AD, Duquette P, Herrera B, Yee IM, Ebers GC: A timing-of-birth effect on multiple sclerosis clinical phenotype. Neurology 2007;69:60-62.

$>13$ Willer CJ, Dyment DA, Sadovnick AD, Rothwell PM, Murray TJ, Ebers GC: Timing of birth and risk of multiple sclerosis: population based study. BMJ 2005;330:120.

14 Sadovnick AD, Yee IM: Season of birth in multiple sclerosis. Acta Neurol Scand 1994; 89:190-191.
15 Ebers GC, Sadovnick AD, Dyment DA, Yee IM, Willer CJ, Risch N: Parent-of-origin effect in multiple sclerosis: observations in half-siblings. Lancet 2004;363:1773-1774.

16 Dean G: Annual incidence, prevalence, and mortality of multiple sclerosis in white South-African-born and in white immigrants to South Africa. Br Med J 1967;ii:724730 .

17 van der Mei IA, Ponsonby AL, Dwyer T, et al: Past exposure to sun, skin phenotype, and risk of multiple sclerosis: case-control study. BMJ 2003;327:316.

18 Munger KL, Levin LI, Hollis BW, Howard NS, Ascherio A: Serum 25-hydroxyvitamin $D$ levels and risk of multiple sclerosis. JAMA 2006;296:2832-2838.

19 Levin LI, Munger KL, Rubertone MV, et al: Multiple sclerosis and Epstein-Barr virus. JAMA 2003;289:1533-1536.

20 Thacker EL, Mirzaei F, Ascherio A: Infectious mononucleosis and risk for multiple sclerosis: a meta-analysis. Ann Neurol 2006 59:499-503.

21 Culpepper WJ 2nd: Effectiveness of Practice Guidelines for Disease Modifying Therapy in Multiple Sclerosis within the Veteran's Heath Administration. Department of Epidemiology and Preventive Medicine. Baltimore, University of Maryland, 2008.

22 Culpepper WJ 2nd, Ehrmantraut M, Wallin MT, Flannery K, Bradham DD: Veterans Health Administration multiple sclerosis surveillance registry: the problem of casefinding from administrative databases. J Rehabil Res Dev 2006;43:17-24.

23 Edwards P, Roberts I, Clarke M, et al: In creasing response rates to postal questionnaires: systematic review. BMJ 2002;324 1183.

24 Confavreux C, Vukusic S: Natural history of multiple sclerosis: a unifying concept. Brain 2006;129:606-616.

25 Jacobs LD, Wende KE, Brownscheidle CM, et al: A profile of multiple sclerosis: the New York State Multiple Sclerosis Consortium. Mult Scler 1999;5:369-376.
26 Minden SL, Frankel D, Hadden L, Perloffp J, Srinath KP, Hoaglin DC: The Sonya Slifka Longitudinal Multiple Sclerosis Study: methods and sample characteristics. Mult Scler 2006;12:24-38.

27 US Geological Survey: Department of the Interior/USGS.

28 United States Department of Commerce: Maps pf Annual Mean Daily Solar Radiation for the United States. Washington, US Government Printing Office, 1974.

29 Hanson RL: Evapotranspiration and droughts; in Paulson RW, Chase EB, Roberts RS, Moody DW (eds): National Water Summary 1988-89: Hydrologic Events and Floods and Droughts. US Geological Survey, 1991, pp 99-104. http://geochange.er.usgs. gov/sw/changes/natural/et/.

30 Garland CF, Garland FC: Do sunlight and vitamin D reduce the likelihood of colon cancer? Int J Epidemiol 1980;9:227-231.

-31 Freedman DM, Dosemeci M, Alavanja MC: Mortality from multiple sclerosis and exposure to residential and occupational solar radiation: a case-control study based on death certificates. Occup Environ Med 2000;57: 418-421.

32 Kurtzke JF, Page WF, Murphy FM, Norman JE Jr: Epidemiology of multiple sclerosis in US veterans. 4. Age at onset. Neuroepidemiology 1992;11:226-235.

33 van der Mei IA, Ponsonby AL, Blizzard L, Dwyer T: Regional variation in multiple sclerosis prevalence in Australia and its association with ambient ultraviolet radiation. Neuroepidemiology 2001;20:168-174

34 Smolders J, Damoiseaux J, Menheere P, Hupperts R: Vitamin D as an immune modulator in multiple sclerosis, a review. J Neuroimmunol 2008; 194:7-17.

35 Hayes CE: Vitamin D: a natural inhibitor of multiple sclerosis. Proc Nutr Soc 2000;59: 531-535.

36 Pugliatti M, Riise T, Sotgiu MA, et al: Evidence of early childhood as the susceptibility period in multiple sclerosis: space-time cluster analysis in a Sardinian population. Am J Epidemiol 2006;164:326-333.

>37 Marrie RA, Horwitz R, Cutter G, Tyry T, Campagnolo D, Vollmer T: Comorbidity delays diagnosis and increases disability at diagnosis in MS. Neurology 2009;72:117-124. 